\title{
DESENVOLVIMENTO DE COLEÇÕES EM BIBLIOTECAS UNIVERSITÁRIAS
}

\section{Ana Cláudia Carvalho de Miranda}

\section{Resumo}

Aborda o gerenciamento da política de desenvolvimento de materiais informacionais nas bibliotecas universitárias. Enfatiza a necessidade de as instituições estabelecerem normas e padrões que orientem o processo decisório, a fim de determinar a conveniência de se adquirir, manter e descartar coleções. Finaliza relacionando os critérios de seleção para formação ideal de um acervo, que atenda às reais necessidades da comunidade acadêmica.

\section{Palavras-chave}

Biblioteca universitária. Desenvolvimento de coleções. Política de seleção. Materiais informacionais - gerenciamento.

\section{COLLECTION DEVELOPMENT IN UNIVERSITY LIBRARIES}

\begin{abstract}
Studies the management related to the development of informative material in university libraries. Emphasizes the need that institutions have to establish norms and patterns to guide the decision making process, in order to determine the convenience to acquire, maintain and discard collections. Finalizes relating the ideal selection criteria to organize an asset, which provides the real necessities of the academic community.
\end{abstract}

\section{Key words}

University library. Collection Development. Selection Politics. Informative Materials Management. 


\section{INTRODUÇÃO}

No cenário atual, a sociedade da informação é marcada pelo fluxo constante de informações que possibilitam a produção de novos conhecimentos, em virtude do grande volume informacional e do desenvolvimento tecnológico, podendo, assim, atuar nas várias áreas do conhecimento, contribuindo na tomada de decisão nos vários grupos sociais.

De acordo com Dias e Pires (2003), o fornecimento de informações é a principal função social dos serviços de informação. Le Coadic (1996, p.5) define informação como: "um conhecimento inscrito (gravado) sob a forma escrita (impressa ou numérica), oral ou audiovisual”. A informação empregada, nesse contexto, envolve diversos tipos de fontes de informações: artigos de periódicos, jornais, monografias, dissertações, teses, relatos de experiências, obras de referências (dicionários, enciclopédias etc), materiais especiais (fotos, partituras musicais, atlas etc), bases de dados etc.

No limiar das últimas décadas, a informação tornou-se a mais poderosa força de transformação do homem, encontrando-se presente no cotidiano do indivíduo através das relações sociais, econômicas e culturais e, adquirindo, neste sentido, um caráter decisivo para o alcance da cidadania, das metas e dos objetivos propostos pelo próprio homem, que cria um vínculo de dependência com a informação para sua melhor adaptação ao meio em que vive. A informação, quando usada sabiamente, contribui como instrumento formador da consciência crítica do indivíduo, podendo levá-lo à conquista do sucesso intelectual e profissional, caso contrário, pode levá-lo ao fracasso e à própria estagnação.

Barreto (2003) reforça essa idéia ao afirmar que a informação, quando assimilada adequadamente, gera novo conhecimento, alterando o estoque mental de informações do indivíduo e traz ganhos ao seu progresso e ao desenvolvimento do seu grupo.

A informação hoje adquire uma característica de mercadoria, ou seja, algo que pode ser capitalizado e que proporciona diversidade de oportunidades; enquanto mercadoria, assume força de poder. 
No tocante à formação de acervos de biblioteca o diferencial se dá pela filtragem adequada das informações obedecendo a padrões estabelecidos de seleção que garantam a disponibilidade de obras confiáveis nos diversos suportes informacionais. Assim sendo, é imprescindível conhecer as necessidades da comunidade a fim de permitir um planejamento com qualidade e eficácia no desenvolvimento e formação das coleções.

Para que a informação tenha qualidade é necessário que seja relevante, confiável, atual, acessível, precisa, oportuna e deve ser ajustada às demandas e expectativas dos usuários. O valor da informação está associado à utilidade que ela apresenta para o público a quem se destina.

Para Dias e Pires (2003), a visão atual da biblioteca como centro ou unidade de informação difere de sua idéia convencional. Essa mudança origina-se da valorização da informação em todos os campos de atividades no mundo contemporâneo. A informação é considerada por autores das diversas áreas do conhecimento como "recurso indispensável" e, no entanto, deve estar à disposição e a serviço de todos: sociedade, instituições, indivíduos etc.

\section{BIBLIOTECA UNIVERSITÁRIA}

As bibliotecas universitárias atuam como órgãos de apoio informacional, dando suporte às atividades de ensino, pesquisa e extensão, com seus acervos quer centralizados ou descentralizados (bibliotecas setoriais). Seus objetivos provêm da finalidade da própria universidade.

Prado (1992) considera a biblioteca universitária como a universidade em si mesma. As universidades são centros transmissores do saber por meio do ensino e dos materiais informacionais. A biblioteca sempre trabalhou em parceria com a universidade, desempenhado a função de preservar e disseminar o conhecimento. Dias e Pires (2003) 
apresentam outras funções da biblioteca universitária: prover informações referenciais e bibliográficas específicas, essenciais ao ensino e à pesquisa. O seu diferencial com relação a outras unidades de informação ocorre em virtude de a educação ser a base do planejamento e seus usuários serem heterogêneos.

O principal papel da biblioteca universitária é atender as necessidades informacionais da comunidade acadêmica (corpo docente, discente, pesquisadores e técnico-administrativo), direcionando sua coleção aos conteúdos programáticos ou em projetos acadêmicos dos cursos ministrados pela universidade a qual encontra-se inserida.

Machado e Silva (2002) ressaltam em nível nacional que o acervo das bibliotecas universitárias é detentor das maiores coleções em Ciência e Tecnologia do país. Mas apesar da sua relevância, essa instituição tem passado por uma série de crises, salvo algumas exceções, que vêm crescendo ao longo dos anos.

Partindo desse pressuposto, os acervos também enfrentam dificuldades, pois apresentam em quantidade insuficiente para atender a demanda, com coleções incompletas e desatualizadas. Geralmente esse quadro é característico de universidades públicas, pois nas instituições privadas em virtude do controle do Ministério da Educação e Cultura (MEC) e da exigência da clientela, reverte a uma realidade menos deficitária, onde a preocupação com a manutenção e preservação de uma coleção que satisfaça a demanda é uma meta constante.

Porém, em relação a formar e desenvolver coleções de materiais informacionais das bibliotecas universitárias no cenário da globalização, quando a informação se multiplica em passo acelerado, e aí surge uma dúvida: como manter e desenvolver uma coleção atualizada e adequada? Isto, por sua vez, conduz o bibliotecário a redefinir e esquecer antigos paradigmas, para estabelecer normas para seleção, aquisição e descarte de materiais, tendo como base critérios previamente definidos para a formação de uma coleção ideal. 


\section{PROCESSO DE DESENVOLVIMENTO DE COLEÇÕES}

Antigamente ocorria uma enorme preocupação, por parte dos responsáveis pelas bibliotecas, arquivos e outras unidades de informações, em aglomerar materiais bibliográficos, uma vez que acervos com grande quantidade de volumes representavam garantia de status e poder, e o foco estava centrado na oferta de documentos e não na qualidade.

Com a explosão da informação e a evolução das tecnologias da informação, a produção e circulação do conhecimento aumentaram vertiginosamente, tendo como conseqüência: a impossibilidade de manter uma coleção completa e auto-suficiente; a impossibilidade de atender todas as demandas e necessidades informacionais da clientela com recursos próprios, em razão dos orçamentos escassos. No entanto, torna-se essencial a realização de um planejamento eficiente no tocante ao crescimento dos acervos, e assim, entra em ação o processo de desenvolvimento das coleções. Segundo Miranda (2004) “desenvolver coleções implica em sistematizar e criar procedimentos para seleção, aquisição, avaliação e desbastamento do acervo”.

As coleções precisam evoluir harmoniosamente em todas as áreas do acervo, para evitar que o mesmo cresça desordenadamente, sem metas ou objetivos definidos. Entretanto, Figueiredo (1999) recomenda que a coleção precisa ser equilibrada, tomando por base os relatórios estatísticos em coleta regular: onde for constatado maior uso, a coleção deverá ser fortalecida; em caso contrário, poderá ser mais fraca, e para área de assunto sem demanda, não é preciso manter acervo algum. O importante é ter conhecimento de outras bibliotecas onde os usuários possam ser encaminhados e atingirem a plena satisfação de suas necessidades informacionais.

Conforme apresenta Vergueiro (1989), o processo de desenvolvimento de coleções é ininterrupto, uma atividade regular e permanente, respeitando a especificidade de cada tipo

(c) Revista Digital de Biblioteconomia e Ciência da Informação, Campinas, v. 4, n. 2, p. 01-19, jan.jun. 2007 - ISSN: 1678-765X. 
de unidade de informação em função dos seus objetivos e público, sem que uma etapa chegue a se distinguir das outras.

A determinação de normas para seleção e aquisição de materiais informacionais disciplina esse processo, tanto em quantidade como em qualidade, segundo a realidade de cada biblioteca, direcionando o uso racional dos recursos financeiros.

Depois de concluído o diagnóstico, seráo tomadoa algumas decisões das políticas que conduzirão o processo de formação do acervo. Dentre as quais Maciel (2000), destaca as seguintes:

- determinação das áreas que farão parte do acervo;

- indicação do tipo de material que irá compor o acervo, independente do seu suporte físico;

- estabelecimento dos critérios e prioridades que orientarão todo o processo, incluindo as decisões nas etapas de seleção, aquisição, e também o desbastamento da coleção, indicando o que deve ser transferido para depósitos especiais ou mesmo serem descartados;

- estabelecimento de diretrizes para a avaliação das coleções, até mesmo com indicação da periodicidade com que deverá ser realizada;

- definição da quantidade de exemplares por título, especialmente para as coleções de uso correntes;

- estabelecimento de diretrizes para a preservação e conservação do acervo, contendo informações sobre as condições ambientais ideais para cada tipo de documento;

- determinação de prazos para revisão das políticas.

Finalizada a elaboração das políticas, obteremos um documento administrativo oficializado perante os dirigentes da instituição designado "Política de Desenvolvimento de coleções”, que deverá ser revisada a cada 02 (dois) anos, pela Comissão de Biblioteca com 
a finalidade de garantir a sua adequação à comunidade acadêmica e aos objetivos da instituição. Romani e Borszcz (2006) recomendam que esta comissão seja composta por:

- 1 bibliotecário, responsável pela unidade de informação;

- 1 representante das principais áreas de atuação (ou departamentos acadêmicos) da instituição à qual está diretamente subordinada;

- 1 representante da área administrativa (setor de compras).

Recomenda-se que a coordenação dessa comissão seja de responsabilidade do bibliotecário, o qual precisará convocar os demais membros para reuniões periódicas e/ou reuniões extraordinárias. Quando ocorrer impossibilidade de agrupar a comissão, o bibliotecário tem o poder de decisão.

Para efetivação do processo como um todo, faz-se mister a elaboração e adoção de parâmetros através da criação de critérios sólidos que estabeleçam critérios para garantir a qualidade no gerenciamento das tomada de decisões relacionadas com a incorporação ou a retirada definitiva de materiais pertencentes ao acervo.

\section{POLÍTICA DE DESENVOLVIMENTO DE COLEÇÕES}

Segundo Vergueiro (1989), a política de desenvolvimento de coleções irá funcionar como parâmetros que contribuirá na tomada de decisão dos bibliotecários em relação à escolha do material a ser acionado ao acervo e à própria administração dos recursos informacionais. A política fornecerá uma exposição do estado geral da coleção, demonstrando o método para alcançar os objetivos e dar subsídios para os bibliotecários argumentarem com as autoridades superiores, tanto para a liberação de novas aquisições como para recusas incoerentes.

Para elaboração da política é imprescindível ter ciência de alguns dados para apreciação tais como: o estado atual da coleção; quais áreas do conhecimento são de maior 
interesse; as necessidades informacionais da clientela a ser servida; o conhecimento dos objetivos da universidade em que a biblioteca está inserida.

Na preparação da política é necessário que sejam estabelecidos os objetivos para dar um maior direcionamento do acervo, visando:

- possibilitar um crescimento racional e equilibrado do acervo de forma qualitativa e quantitativa;

- garantir a continuidade e a adequação necessárias à formação da coleção;

- determinar os critérios para duplicação de títulos;

- estabelecer as prioridades de aquisição de material;

- conhecer as necessidades dos usuários, através da análise de uso das coleções e sua atualidade;

- estabelecer critérios para intercâmbio de materiais informacionais;

- acompanhar o surgimento dos novos suportes de informação, não se limitando apenas, ao suporte em papel;

- buscar atender a todos as sugestões, deixando o solicitado informado da aquisição ou não do item sugerido;

- identificar critérios para recebimento de doações, descarte e reposição de material;

Uma das etapas mais importante da política de desenvolvimento de coleções é o processo de seleção, pois através dele são estabelecidos os critérios que garantem a qualidade e o ajustamento para atender a contento as reais necessidades dos usuários.

\section{PROCESSO DE SELEÇÃO DO ACERVO}

Conforme salienta Vergueiro (1995) “a seleção é um momento de decisão”, momento em que apenas, num simples ato, o bibliotecário decide o universo de informações a que seus usuários terão acesso, ou seja, o bibliotecário detém o poder de compor a coleção. No 
entanto, na biblioteca universitária esse procedimento ocorre baseado nos planos de ensino e suas respectivas bibliografias.

Segundo Figueiredo (1991), este processo quando bem executado irá garantir que a qualidade e o tamanho da coleção estejam em concordância com as necessidades informacionais dos usuários. É, portanto, uma atividade meramente intelectual que precisa ser executada por um profissional competente no assunto, em co-participação estreita com os usuários.

A seleção numa biblioteca universitária deve ser feita em parceria dos bibliotecários com corpo docente, pois estes dominam a literatura nas suas respectivas áreas e podem assim, selecionar criteriosamente o material a ser obtido, arrolando-os através dos Planos de Ensino. Os bibliotecários devem permanecer cientes das exigências do MEC para composição do acervo no que se refere à qualidade e à quantidade mínima de títulos e exemplares. No tocante à quantidade, deve ser determinado um percentual de exemplares destinados à literatura básica e outro para a literatura complementar.

\subsection{Seleção da literatura básica}

A literatura básica, como o próprio nome já destaca, é imprescindível para o andamento das atividades acadêmicas, ou seja, é obrigatória na formação da coleção, devendo ser adequada, pertinente, atualizada e com relevância acadêmico-científica. O Ministério da Educação recomenda, para material nacional, que em cada 10 (dez) alunos matriculados por disciplina, 01 (um) exemplar deverá ser adquirido, sendo importante acompanhar o crescimento da instituição, verificando o surgimento de novos cursos, como também a ampliação na oferta de vagas. A biblioteca precisará formar seu acervo destinado à consulta local, onde 01 (um) exemplar da coleção básica permanecerá na coleção.

Quanto à literatura estrangeira aconselha-se adquirir quando não existir uma tradução em português ou espanhol. Nesse caso, o indicado em relação ao livro-texto 
estrangeiro, sua aquisição não obedece aos critérios estabelecidos para nacionais. Essa redução ocorre devido este material ser destinado principalmente ao corpo docente e discente da pós-graduação, os quais constituem um grupo de usuários reduzidos e com necessidades específicas, além do baixo número de leitores que dominam outros idiomas.

\subsection{Seleção da literatura complementar}

O acervo de literatura complementar é formado por materiais informacionais essenciais à complementação e atualização voltados para pesquisa e ensino nas várias áreas do conhecimento, indicados nos planos de ensino. Para composição dessa coleção é sugerido adquirir 03 (três) exemplares desse material, respeitando a demanda, porém quando a procura for expressiva que justificar a necessidade de uma quantidade superior de exemplares.

Também podem fazer parte dessa coleção obras nacionais e estrangeiras não mencionadas nos planos de ensino, mas que complementem o acervo de acordo com as exigências do MEC e sugestões e demandas da comunidade acadêmica. A duplicação desse acervo fica a critério de cada biblioteca estabelecê-la dentro da sua realidade.

\subsection{Seleção de periódicos}

Os periódicos são considerados uma fonte de informação primária, pois abordam informações novas, fatos, acontecimentos ou novas interpretações de teorias, sendo indispensáveis na divulgação dos resultados de pesquisas e relatos de experiências recentes, facilitando o acompanhamento constante dos avanços em cada área, favorecendo a necessária realimentação do ciclo de geração de comunicação e disseminação mais rápida de novos conhecimentos. Os periódicos podem abordar assunto específico ou abranger mais de uma área do conhecimento, dependendo da limitação de sua cobertura.

Prado (1992, p. 103) adverte:

o periódico caminha muito mais a par da ciência do que os livros, pois pesquisas, descobertas ou observações chegarão, através dos periódicos, no mesmo mês ou 
na mesma semana às mãos, ao passo que o livro, embora com mais detalhes e estudo mais profundo só será obtido, na melhor das hipóteses, meses depois.

Diante dessa realidade, o periódico representa um material importante para a comunidade acadêmica; deve-se adotar um compromisso com a sua continuidade na coleção, após assiná-lo. Vergueiro (1997) adverte que esse compromisso é por tempo indeterminado, e também compromete um percentual considerável do orçamento da biblioteca, sendo essencial avaliar permanentemente os custos.

As bibliotecas universitárias precisam compor sua coleção com periódicos que abordem assuntos gerais e específicos (locais, regionais, nacionais e internacionais), porém como são muitas as publicações, cada biblioteca deverá determinar seus critérios que contemplem a prioridade de aquisição das mesmas, relacionados aos planos de ensino, aos cursos oferecidos pela instituição e aos cursos em fase de reconhecimento, implantação, credenciamento ou recredenciamento.

Atualmente, as bibliotecas acadêmicas assinam portais eletrônicos que implicam a atualização mais rápida da coleção de periódicos, propiciando, também economia de espaço. As bibliotecas das universidades públicas e dos CEFET’s, possuem acesso a Portal de Periódicos: uma biblioteca virtual de informação científico-tecnológica mundial, oferecido pelo Governo Brasileiro e mantido pela CAPES. O Portal disponibiliza conteúdo atualizado e de alta qualidade, permitindo consultas e acesso aos artigos científicos completos. São mais de nove mil títulos de artigos científicos, com 181 instituições de educação superior usuárias do serviço.

Para julgar a qualidade de um periódico, Vergueiro (1995) destaca dois indicadores: primeiramente, a opinião de um especialista e segundo, a análise das informações da contracapa ou das páginas iniciais.

É indicado realizar uma avaliação no acervo dos periódicos correntes, no intervalo de 05 (cinco) anos, buscando a obtenção de dados que justifiquem a continuidade ou 
interrupção da assinatura dos memos, ou até assinar um outro título que satisfaça mais ao público. O relatório elaborado após essa análise deverá ser encaminhado aos departamentos para julgamento dos professores e, assim, ser tomada a medida mais recomendada para cada título em questão.

\subsection{Critérios para seleção}

Para garantir a qualidade na aquisição de novos materiais é necessário que sejam estabelecidos critérios para seleção, estes devem tomar por base dois fatores decisivos: o interesse da comunidade a ser servida e os recursos financeiros destinados para a aquisição.

A determinação dos critérios assegura que o acervo seja produto de um planejamento voltado para as diretrizes e objetivos da Universidade. Seguem abaixo, alguns critérios de seleção para o desenvolvimento do acervo:

- adequação do material às ementas e ao projeto pedagógico dos cursos;

- autoridade do autor e/ou editor;

- atualidade técnico-científica dos conteúdos;

- qualidade técnica;

- $\quad$ escassez de material sobre o assunto na coleção da Biblioteca;

- aparecimento do título em bibliografias e índices;

- cobertura/tratamento;

- custo justificado;

- idioma acessível;

- relevância/interesse acadêmico-científicos;

- número de usuários potenciais que poderão utilizar o material;

- condições físicas do material.

Estes critérios são somente uma sugestão e nem sempre são adotados em todos os documentos, sendo necessário um ajuste para cada biblioteca, conforme a sua realidade e seus objetivos. Uma das etapas subseqüentes é a do processo de aquisição. 


\title{
6 PROCESSO DE AQUISIÇÃO
}

O processo de aquisição é a execução das decisões tomadas no processo de seleção, ou seja, é o procedimento destinado à obtenção dos documentos.

A aquisição pode ocorrer através de três modalidades: compra, doação e permuta. A concretização deste processo por compra requer um criterioso trabalho por parte do profissional encarregado, para sua devida concretização e correspondência perfeita com o material selecionado. Já em relação à doação e a permuta não exige tanto empenho do profissional, porém todos os materiais originários destas modalidades devem ser analisados antes de incorporá-los ao acervo, para não criar uma coleção imensa, porém fora da realidade aos interesses a que se destina.

As atividades relativas à aquisição por compra são bastante complexas, como podemos observar no relato abaixo:

\begin{abstract}
À aquisição caberá o trabalho minucioso de identificação, localização dos itens e sua posterior obtenção para o acervo, qualquer que seja a maneira de tornar isto possível. E não è uma tarefa assim tão automática, pois, infelizmente para os profissionais, os títulos selecionados não se encontram acenando para eles ao dobrar da esquina, a gritar 'olha eu aqui, olha eu aqui' e quase implorando para serem adquiridos. Muitas vezes, realizar um trabalho de aquisição assemelha-se a procurar uma agulha em palheiro, tantas são as possibilidades e dificuldades existentes. É uma atividade que exige perseverança e atenção a detalhes, de maneira a evitar um descompasso entre o que foi escolhido primeiramente para aquisição e aquilo que chega às mãos do usuário. (ANDRADE, 1996, p.6).
\end{abstract}

A aquisição envolve dois itens básicos: orçamento e alocação de recursos. Antes da compra devem ser previamente definidos os recursos financeiros, para permitir uma visão concreta do que se pode contar. Andrade (1996) salienta que, na prática, o orçamento previsto para aquisição de materiais nem sempre corresponde aos recursos liberados, ocasionando que nem todas as necessidades consideradas prioritárias serão atendidas. 
Vale advertir que parte da verba para aquisição de materiais informacionais deve ser reservado para assinatura de periódicos, compra de multimeios, obras raras, assinaturas de bases de dados, entre outros.

\section{AVALIAÇÃO DA COLEÇÃO}

A avaliação da coleção deve ser sistemática e entendida como um processo empregado para determinar a importância e a adequação do acervo com os objetivos da Biblioteca e da instituição, possibilitando traçar parâmetros quanto à aquisição, à acessibilidade e ao descarte.

Ao iniciar-se a avaliação do acervo deve ser verificado:

O que a biblioteca deveria possuir e não possui, e o que possui, mas não deveria possuir, tendo em vista fatores de qualidade e adequação da literatura publicada, sua observância, as mudanças de interesses dos usuários, e a necessidade de otimizar o uso de recursos financeiros limitados. (LANCASTER, 1996, p. 20).

Os métodos utilizados para avaliar o acervo são: quantitativos (tamanho e crescimento) e qualitativos (julgamento por especialistas, análise do uso real), em que os resultados são comparados e analisados, assegurando o alcance dos objetivos da avaliação da coleção, garantindo uma melhor qualidade da política de desenvolvimento de coleções.

A avaliação qualitativa por meio do julgamento por especialistas num assunto pode trazer alguns problemas, conforme destaca Lancaster (1996): o especialista talvez não seja completamente imparcial, como também, não está familiarizado com a comunidade que a biblioteca atende.

Figueiredo (1991) enfatiza que um meio para realizar a avaliação é através da análise comparativa do que é comprado, verso o uso subseqüente; esta análise favorece o melhoramento da seleção, quer pela identificação dos tipos de material com pouca chance de ser utilizado, quer pela alteração no processo de seleção que acarreta em compra de materiais desnecessários para a clientela. 
Na avaliação do acervo são sugeridos os seguintes critérios:

a) Distribuição percentual do acervo por área

b) A análise das estatísticas de uso do material consistirá na determinação dos títulos que requerem mais exemplares e daquele cuja duplicação é desnecessária.

Em contrapartida, se for confirmada a sub-utilização dos recursos bibliográficos em alguma área, a Biblioteca deverá averiguar a causa do problema, que pode estar nafalta de qualidade do material existente, desatualização, falha de interesse, desconhecimento da existência da obra, etc.

A análise comprovará quais as áreas que devem ter a suas coleções inovadas (seja em exemplares, títulos nacionais ou internacionais etc.) e quais as áreas de pesquisa encontram-se desprovidas de materiais informacionais que necessitam de providências.

c) Sugestões dos clientes

d) A sugestão do usuário é um parâmetro seguro para se avaliar as coleções e, portanto, através da mesma poder-se-á:

- verificar se a coleção satisfaz aos usuários;

- determinar os tipos e níveis de necessidade em relação às coleções;

- coletar sugestões e indicações para futuras aquisições;

- verificar as mudanças de interesse por parte da clientela.

- comparação das coleções com planos de ensino, catálogos e bibliografias recomendados.

O emprego desse método incidiu na comparação do acervo com planos de ensino, bibliografias recomendadas e/ou adotadas, para examinar os itens não existentes na biblioteca e quais devem ser adquiridos. 


\section{DESBASTAMENTO DE MATERIAL INFORMACIONAL}

Desbastamento é o processo pelo qual se exclui do acervo ativo, títulos e/ou exemplares, partes de coleções, quer para remanejamento, descarte ou conservação (restauração). É um processo contínuo e sistemático, para conservar a qualidade da coleção, ocorrendo sempre devido a necessidade de um processo constante de avaliação da coleção e deve ser feito de acordo com as necessidades da Biblioteca e com o julgamento da Comissão de Biblioteca num prazo que varia entre 03 (três) a 05 (cinco) anos.

O desbastamento não se refere apenas a um simples expurgo de materiais, apesar de englobá-lo no descarte.

\subsection{Descarte}

É a retirada definitiva dos materiais que não possuem nenhuma justificativa para continuar pertencendo ao acervo.

Processo pelo qual, após ser avaliado criteriosamente, o material desatualizado ou inadequado é retirado ou não incluído na coleção ativa, não tem fundamento guardar material que não correspondam mais aos interesses dos usuários, além de possibilitar a economia de espaço, maior facilidade de acesso ao acervo e mais eficiência no atendimento ao usuário.

Dentre todas as atividades inerentes ao desbastamento, a que exige maior cuidado e segurança, por parte do bibliotecário é o descarte, conforme Vergueiro (1989, p.75) enfatiza bem esta dificuldade.

Afinal - pergunta-se o bibliotecário -, quando se descartar? E para quê? São perguntas quê, deve-se reconhecer, constituem reais dilemas para profissionais que tiveram toda uma educação (não apenas a superior) para conservar os materiais informacionais, sob sua responsabilidade, da melhor forma possível, a fim de que os mesmos pudessem vir a ser utilizado pela coletividade - ou, ao menos, conservados para uma geração futura. 
Para uma maior eficácia desta atividade é recomendado que se apliquem os mesmos critérios usados no processo de seleção, no momento da apreciação para exclusão dos materiais informacionais pela comissão responsável, pois da mesma forma como seleciona os materiais que devem incorporar ao acervo também é imprescindível que sejam selecionados os propensos à retirada definitiva.

\section{CONSIDERAÇÕES FINAIS}

Com base nas reflexões propostas, pode-se confirmar que o papel da biblioteca universitária é munir o corpo docente, discente e técnico-administrativo de informação para dar suporte às atividades de ensino, pesquisa e extensão, voltados aos planos de ensino ou em projetos acadêmicos de cada departamento.

$\mathrm{Na}$ atual conjuntura, a informação se multiplica rapidamente, possibilitando a produção de novos conhecimentos: em virtude do grande volume informacional, surge uma dúvida: como manter uma coleção adequada e atualizada que atenda a demanda e as necessidades do público.

Nesse cenário, o desenvolvimento de coleções dever ser um processo ininterrupto permanecendo em constante evolução. No entanto, é necessário elaborar uma política de desenvolvimento da coleção que conglomere os objetivos dos planos de ensino da instituição, no tocante a englobar a literatura básica e complementar, com a finalidade de subsidiar a tomada de decisão no processo de seleção, considerando todos os fatores relevantes aos interesses da comunidade acadêmica, como também avaliar a coleção periodicamente para preservar a qualidade e a idoneidade do acervo.

A atribuição de critérios na seleção assegura que a coleção é produto de um planejamento totalmente adequado às ementas, aos projetos pedagógicos dos cursos e aos objetivos da Universidade/Faculdade. 
A qualidade no gerenciamento de materiais informacionais encontra-se fundamentada na elaboração de uma política de desenvolvimento de coleções, condicionada à flexibilidade para alterar ou ajustar as mudanças nos planos de ensino sempre que for constatado que a biblioteca não está satisfazendo aos seus usuários, buscando adequá-la às atuais necessidades acadêmicas.

\section{REFERÊNCIAS}

ANDRADE, D.; VERGUEIRO, W. Aquisição de materiais de informação. Brasília: Briquet de Lemos, 1996.

BARRETO, A. A. A questão da informação. Disponível em: <http://www.alternex.com.br/ aldoibct/quest/quest.htm>. Acesso em: 25 ago. 2003.

BRASIL. Ministério da Educação. Secretaria de Educação Superior. Disponível em: $<$ http://portal.mec.gov.br/sesu/>. Acesso: em 18 jan. 2007.

DIAS, M. M. K.; PIRES, D. Formação e desenvolvimento de coleções de serviços de informação. São Carlos: EdUFSCar, 2003.

FIGUEIREDO, N. M. Metodologias para a promoção do uso da informação: técnicas aplicadas particularmente em bibliotecas universitárias e especializadas. São Paulo: Nobel, 1991.

LE COADIC, Yves-François. A ciência da informação. Brasília: Briquet de Lemos, 1996.

LANCASTER, F. W. Avaliação de serviços de bibliotecas. Brasília: Briquet de Lemos, 1996.

MACHADO, R. N.; SILVA, Z. P. Desenvolvimento de coleções: uma análise a partir dos anais dos SNBUs realizados na década de 90. In: SEMINÁRIO NACIONAL DE BIBLIOTECAS UNIVERSITÁRIAS, 12., 2002, Recife. Anais... Recife: UFPE, 2002.

MACIEL, A. C.; MENDONÇA, M. A. R. Bibliotecas como organizações. Rio de Janeiro: Interciência, 2000.

MIRANDA, A. C. C. A política de desenvolvimento de coleções no âmbito da informação jurídica. In: PASSOS, Edilenice (Org.). Informação jurídica: teoria e prática. Brasília: Thesaurus, 2004.

MULLER, S. P. M. A ciência, o sistema de comunicação científica e a literatura científica. In: CAMPELO, Bernadete Santos (Org.). Fontes de informação para pesquisadores e profissionais. Belo Horizonte: UFMG, 2000.

ROMANI, C.; BORSZCZ, I. (Orgs.). Unidades de informação: conceitos e competências. Florianópolis: Ed. Da UFSC, 2006.

VERGUEIRO, W. C. S. Desenvolvimento de coleções. São Paulo: Polis, 1989.

. Seleção de materiais de informação. 2. ed. Brasília. 


\section{Ana Cláudia Carvalho de Miranda}

Especialista em Gestão da Qualidade Total pela UFRN. Especialista em Gestão Estratégica de Pessoas pela Facex. Graduada em Biblioteconomia pela UFC. Chefe da Biblioteca do Tribunal de Justiça do RN.

anaclaudia@tirn.gov.br 